\title{
Improving the Activity of Students Through the Implementation of The Picture and Picture Assisted Media Visual Audio Media in SDN Citembong 01 Bantarsari
}

\author{
Khaeruman \\ SD Negeri Citembong 01 Bantarsari \\ Khaeruman.almuhajirin@gmail.com
}

\section{Article History}

accepted $14 / 11 / 2020$

approved $21 / 11 / 2020$

published 26/11/2020

\begin{abstract}
The purpose of this research was to improve student learning outcomes in science grade $V$ elementary schools with a Google meet assisted Project Based Learning (Picture and Picture) learning model. The research conducted was a Classroom Action Research (PTK) with three cycles, with each cycle consisting of two meetings. The stages of each cycle are planning, implementing, observing and reflecting. Each meeting is carried out a pre test and post test to determine the progress of students. In the first cycle the students who completed after carrying out the post test were $74 \%$. In the second cycle students who completed after carrying out the post test were $87 \%$. In the third cycle students who completed after carrying out the post test were 90\%. These results indicate that the Project Based Learning (Picture and Picture) learning model can improve student learning outcomes, especially grade V science at SDN 2 Cilongok.
\end{abstract}

Keywords: Learning outcomes, project based learning, science

\section{Abstrak}

Tujuan penelitian ini adalah untuk meningkatkan hasil belajar siswa kelas V SD dengan model pembelajaran Project Based Learning (Picture and Picture) berbantuan Google meeted. Penelitian yang dilakukan adalah Penelitian Tindakan Kelas (PTK) dengan tiga siklus, dengan setiap siklus terdiri dari dua pertemuan. Tahapan setiap siklus adalah perencanaan, pelaksanaan, observasi dan refleksi. Setiap pertemuan dilakukan pre test dan post test untuk mengetahui kemajuan siswa. Pada siklus I siswa yang tuntas setelah melaksanakan post test sebanyak $74 \%$. Pada siklus II siswa yang tuntas setelah melaksanakan post test sebanyak $87 \%$. Pada siklus III siswa yang tuntas setelah melaksanakan post test sebanyak $90 \%$. Hasil tersebut menunjukkan bahwa model pembelajaran Project Based Learning (Picture and Picture) dapat meningkatkan hasil belajar siswa khususnya kelas V IPA di SDN 2 Cilongok.

Kata kunci: Hasil belajar, pembelajaran berbasis proyek, sains

Social, Humanities, and Education Studies (SHEs): Conference Series https://jurnal.uns.ac.id/shes

p-ISSN 2620-9284

e-ISSN 2620-9292 


\section{PENDAHULUAN}

Semua Guru atau Peserta didik pasti selalu mengharapkan agar setiap proses belajar mengajar dapat mencapai hasil belajar yang sebaik-baiknya. Guru mengharapkan agar Peserta didik dapat memahami setiap materi yang diajarkan , Peserta didikpun mengharapkan agar Guru dapat menyampaikan atau menjelaskan pelajaran dengan baik, sehingga memperoleh hasil belajar yang memuaskan. Akan tetapi harapan-harapan itu tidak selalu dapat terwujud. Masih banyak Peserta didik yang kurang memahami penjelasan Guru. Ada Peserta didik yang nilainya selalu rendah, bahkan ada Peserta didik yang tidak bisa mengerjakan soal atau jika mengerjakan soalpun jawabannya asal-asalan. Semua itu menunjukkan bahwa Guru harus selalu mengadakan perbaikan secara terus menerus dalam pembelajarannya, agar masalah-masalah kesulitan belajar Peserta didik dapat diatasi, sehingga hasil belajar Peserta didik mencapai tujuan yang diharapkan.

Masalah - masalah yang dialami oleh Peserta didik dalam pembelajaran tidak muncul begitu saja, tetapi ada faktor-faktor penyebabnya. Apabila Guru mampu mengidentifikasi penyebab timbulnya masalah yang dialami oleh Peserta didik, maka Guru tersebut akan dapat melakukan penanganan-penanganan yang tepat dalam memecahkan masalah pembelajarannya. Contoh masalah yang sering muncul dalam pembelajaran yaitu Peserta didik kurang memahami penjelasan Guru, Peserta didik tidak mengerti kata, kalimat, bentuk kalimat, yang diucapkan ataupun yang ditulis. Hal Ini mungkin karena penjelasan Guru tidak disertai alat peraga atau alat peraga kurang atau bahkan tidak sesuai.

Sejujurnya penggunaan alat peraga, media pembelajaran untuk pembelajaran tematik pada muatan pelajaran IPA di SD khususnya masih minim inovasi dilakukan oleh Guru di sekolah. Sehingga minat belajar peserta didik menjadi minim,ini mengakibatkan salah satunya tingkat keaktifan peserta didik menjadi berkurang sehingga akan berakibat fatal diantaranya adalah hasil belajar kurang maksimal. Dengan demikian tujuan pembelajaran yang sudah dirancang sedemikian rupa akan sulit untuk dicapai. Oleh karena itu tugas PTK yang kami laksanakan ini mencoba mengambil tema "PENINGKATAN KEAKTIFAN PESERTA DIDIK MELALUI PENERAPAN MODEL PICTURE AND PICTURE BERBANTU MEDIA AUDIO VISUAL PADA PEMBELAJARAN IPA PESERTA DIDIK KELAS 3 SDN CITEMBONG 01." Tentu saja Penerapan model yang baik harus ditunjang oleh metode yang sesuai dengan materi pelajaran.

ndekatan konstruktivisme dalam proses pembelajaran didasari oleh kenyataan bahwa tiap individu memiliki kemampuan untuk mengkonstruksi kembali pengalaman atau pengetahuan yang telah dimilikinya. Oleh sebab itu dapat dikatakan bahwa pembelajaran konstruktivisme merupakan satu teknik pembelajaran yang melibatkan peserta didik untuk membina sendiri secara aktif pengetahuan dengan menggunakan pengetahuan yang telah ada dalam diri mereka masing-masing. Peserta didik akan mengaitkan materi pembelajaran baru dengan materi pembelajaran lama yang telah ada (Lapono, 2008: 1.25). Terjadinya pergeseran peranan guru dalam pembelajaran konstruktivisme tentunya membawa dampak tertentu, misalnya guru merasa beban mengajarnya menjadi ringan karena membiarkan peserta didik untuk belajar sendiri. Hal ini tidak perlu terjadi karena perspektif konstruktivisme dalam pembelajaran disekolah menitikberatkan pada pengalaman pendidikan yang dirancang untuk membantu peserta didik menguasai ilmu pengetahuan. Peserta didik didorong agar berperan serta secara aktif dalam proses pembelajaran, sedangkan guru hanya akan memainkan peranan sebagai pembimbing atau fasilitator dalam memperkembangkan pengetahuan yang telah ada dalam diri peserta didik (Lapono, 2008: 1.27). 


\section{METODE}

Penelitian ini menggunakan rancangan penelitian tindakan kelas (classroom based action research) yang terdiri atas tiga siklus. Menurut Aqip (2010: 3) penelitian tindakan kelas adalah penelitian dilakukan oleh guru di kelasnya sendiri melalui refleksi diri dengan tujuan memperbaiki kinerjanya sehingga hasil belajar Peserta didik meningkat. Dalam pelaksanaan PTK terdapat 4 tahap penting, yaitu perencanaan, pelaksanaan tindakan, observasi, dan refleksi.

Keempatnya harus terencana sebaik mungkin agar pelaksanaan penelitian dapat terlaksana dan mendapat hasil yang sesuai dengan keinginan peneliti.

Baik pre test maupun post test. Observasi meliputi observasi keterlaksanaan model pembelajaran Picture and picture, sikap peserta didik dan keterampilan. Untuk hasil belajar menggunakan tes melalui Google form.

\section{HASIL DAN PEMBAHASAN}

Bagian ini sebanyak 800-1000 kata. Pada bagian pembahasan, diuraikan hasil kajian/penelitian dan hubungannya dengan kerangka teori atau kajian empirik terdahulu. Pada bagian ini dapat mnyertakan tabel dan gambar secara ringkas. Contoh penyajian tabel dan gambar sebagai berikutPada siklus I pembelajaran dilaksanakan selama dua pertemuan, setiap pertemuan diadakan pre test dan post test. Untuk mengetahui perkembangan peserta didik selama pembelajaran. Siklus I membahas materi tentang Ciri-ciri Makhluk Hidup. Pembelajaran dengan model Picture and Picture dilaksanakan dengan 6 langkah Picture and Picture secara berurutan mulai dari menentukan pertanyaan mendasar, merancang proyek, menyusun jadwal, memantau proses proyek, penilaian hasil dan evaluasi pengalaman. Proyek yang dibuat peserta didik adalah menyusun rantai makanan dengan gambar yang tepat. Berikut ini adalah hasil belajar peserta didik pada siklus I yang bisa dilihat pada tabel berikut.

Tabel 1. Penilaian Hasil Belajar Siklus 1

\begin{tabular}{cccc}
\hline \multirow{2}{*}{ Rata-Rata } & Ketuntasan & Jumlah Peserta didik & Presentase (\%) \\
\hline \multirow{2}{*}{48,20} & Tuntas & 11 & 48,27 \\
& Belum tuntas & 12 & 51,73 \\
\hline
\end{tabular}

Berdasarkan tabel di atas maka terjadi peningkatan antara pre test dan post test pada pertemuan 1. Setiap individu peserta didik sudah mengalami peningkatan hasil belajarnya. Peserta didik mengalami peningkatan hasil belajar pada pertemuan 1. Ketuntasan klasikal juga mengalami peningkatan, pada pre test hanya terdapat 9 anak yang sudah tuntas, tetapi pada post test bertambah menjadi 20 anak yang sudah tuntas dengan Kriteria Ketuntasan Minimal (KKM) sebesar 70. Demikian juga pada pertemuan 2 jumlah peserta didik yang sudah tuntas KKM mengalami peningkatan. Pada pre test ada 11 anak yang baru tuntas, sudah meningkat menjadi 23 peserta didik yang tuntas setelah melaksanakan post test. Perbandingan antara hasil post test pada pertemuan 1 dan pertemuan 2 juga terdapat perbedaan. Pada pertemuan 1 peserta didik yang sudah tuntas hanya ada 20 anak, sedangkan pada pertemuan 2 sudah meningkat menjadi 23 anak. Persentase ketuntasan klasikalnya meningkat, jika pertemuan 1 hanya $67 \%$ maka pada pertemuan 2 menjadi $74 \%$.

Berdasarkan refleksi pada siklus I maka diputuskan untuk melanjutkan ke siklus II dikarenakan belum mencapai ketuntasan klasikal yang diharapkan. Siklus II masih membahas tentang ciri-ciri Makhluk hidup. Pembelajaran dengan model Picture and Picture dilaksanakan dengan 6 langkah Picture and Picture secara berurutan seperti siklus I Proyek yang dibuat peserta didik adalah menyusun jaring-jaring dengan 
gambar yang tepat. Berikut ini adalah hasil belajar peserta didik pada siklus II yang bisa dilihat pada tabel berikut.

Tabel 2. Penilaian Hasil Belajar Siklus 2

\begin{tabular}{cccc}
\hline Rata-Rata & Ketuntasan & Jumlah Peserta didik & Presentase (\%) \\
\hline 82,61 & Tuntas & 19 & 82,61 \\
17,39 & Belum tuntas & 4 & 17,39 \\
\hline
\end{tabular}

Workshop Nasional Penguatan Kompetensi Guru Sekolah Dasar 2020 SHEs: Conference Series 3 (3) (2020) 215 - 220

Berdasarkan tabel di atas maka terjadi peningkatan antara pre test dan post test pada pertemuan 1. Setiap individu peserta didik sudah mengalami peningkatan hasil belajarnya. Ketuntasan klasikal juga mengalami peningkatan, pada pre test hanya terdapat 11 anak yang sudah tuntas, tetapi pada post test bertambah menjadi 19 anak yang sudah tuntas dengan Kriteria Ketuntasan Minimal (KKM) sebesar 70. Demikian juga pada pertemuan 2 jumlah peserta didik yang sudah tuntas KKM mengalami peningkatan. Pada pre test ada 11 anak yang baru tuntas, sudah meningkat menjadi 19 peserta didik yang tuntas setelah melaksanakan post test. Perbandingan antara hasil post test pada pertemuan 1 dan pertemuan 2 juga terdapat perbedaan. Pada pertemuan 1 peserta didik yang sudah tuntas hanya ada 11 anak, sedangkan pada pertemuan 2 sudah meningkat menjadi 19 anak. Persentase ketuntasan klasikalnya meningkat, jika pertemuan 1 hanya $48,73 \%$ maka pada pertemuan 2 menjadi $82,61 \%$.

Setelah melakukan refleksi pada siklus II, maka diputuskan untuk melanjutkan pada siklus III. Hal ini dilakukan agar mengetahui sejauh mana penerapan pembelajaran Picture and Picture tidak hanya meningkatkan tetapi juga mempertahankan hasil belajar peserta didik. Pada siklus III materi yang diajarkan masih membahas sub tema ciri-ciri makhluk hidup, peserta didik mengerjakan proyek sebuah pamflet berisi informasi tentang ciri-ciri Makhluk hidup. Hasil belajar peserta didik dapat dilihat pada tabel berikut.

Tabel 3. Penilaian Hasil Belajar Siklus 3

\begin{tabular}{llll}
\hline Rata-Rata & Ketuntasan & Jumlah Peserta didik & Presentase (\%) \\
\hline 95,65 & Tuntas & 22 & 95,65 \\
4,35 & Belum tuntas & 1 & 4,35 \\
\hline
\end{tabular}

Ketuntasan klasikal mengalami peningkatan, pada pre test hanya terdapat 19 anak yang sudah tuntas, tetapi pada post test bertambah menjadi 22 anak yang sudah tuntas dengan Kriteria Ketuntasan Minimal (KKM) sebesar 70. Demikian juga pada pertemuan 2 jumlah peserta didik yang sudah tuntas KKM mengalami peningkatan. Pada pre test ada 19 anak yang baru tuntas, sudah meningkat menjadi 23 peserta didik yang tuntas setelah melaksanakan post test. Perbandingan antara hasil post test pada pertemuan 1 dan pertemuan 2 juga terdapat perbedaan. Pada pertemuan 1 peserta didik yang sudah tuntas hanya ada 19 anak, sedangkan pada pertemuan 2 sudah meningkat menjadi 23 anak. Persentase ketuntasan klasikalnya meningkat, jika pertemuan 1 hanya 82,61\% maka pada pertemuan 2 menjadi 95,65\%.

Dari tiga siklus yang sudah dilaksanakan selama 6 pertemuan dapat dipastikan bahwa model pembelajaran Picture and Picture dapat meningkatkan keaktifan Peserta didik pada mupel IPA Kelas 3 di SD Negeri Citembong 01 Bantarsari. Hal ini sesuai dengan konsep atau teori yang diungkap oleh Nanang Hanafiah dan Cucu Suhana (2009:30) bahwa langkah penerapan Model pembelajaran ini merupakan model 
pembelajaran inovatif yang melibatkan kerja proyek dimana peserta didik bekerja secara mandiri dalam mengkonstruksi pembelajarannya dan mengkulminasikannya dalam produk nyata. Memang benar adanya dengan model Picture and Picture peserta didik akan membangun sendiri pengetahuannya dengan mengerjakan proyek yang diberikan. Peserta didik dapat memahami Ciri-ciri Makhluk Hidup. Pada siklus II peserta didik juga dapat memahami ciri-ciri Makhluk hidup dalam proyek sehingga pengetahuan yang dihasilkan dapat tertanam dengan permanen. Hasil penelitian ini juga sesuai dengan penelitian sebelumnya yang dilakukan oleh Surya, dkk (2018) yang membuktikan bahwa model pembelajaran Picture and Picture berbantu media audio visual dapat meningkatkan hasil belajar dan kreativitas peserta didik.

\section{SIMPULAN}

Berdasarkan hasil penelitian peningkatan kualitas pembelajaran IPA melalui model Picture and Picture berbantu media audio visual yang sudah peneliti laksanakan di kelas V SDN Citembong 01 Bantarsari, maka dapat disimpulkan sebagai berikut:

1) Pembelajaran IPA melalui model Picture and Picture berbantu media audio visual di kelas 3 SDN Citembong 01 Bantarsari dapat meningkatkan keterampilan guru. Keterampilan guru pada pelaksanaan siklus I tergolong kriteria baik. Pada pelaksanaan siklus II tergolong dalam kriteria baik. Pada siklus III tergolong dalam kriteria sangat baik. Ditunjukkan dengan perolehan skor yang mengalami peningkatan pada setiap siklusnya yaitu: (a)

melaksanakan kegiatan awal; (b) menyampaikan materi pengantar melalui media audio visual; (c) membimbing siswa dalam melaksanakan diskusi kelompok.

2) Pembelajaran IPA melalui model Picture and Picture berbantu media audio visual di kelas 3 SDN Citembong 01 Bantarsari dapat meningkatkan aktivitas siswa. Aktivitas siswa pada pelaksanaan siklus I dengan kriteria cukup. Pada siklus II dengan kriteria baik. Pada siklus III dengan kriteria baik. Ditunjukkan dengan perolehan skor yang mengalami peningkatan pada setiap siklusnya yaitu: (a) siap mengikuti pembelajaran; (b) memperhatikan tayangan materi yang ditampilkan oleh guru; (c) saling bekerjasama dalam

kegiatan berkelompok; (d) memasangkan gambar yang sesuai atau mengurutkan gambar yang acak menjadi urutan yang benar; (e) menyampaikan dasar pemikiran pasangan/ urutan gambar yang telah disusun; (f) mempresentasikan hasil diskusi kelompok; (g) menyimpulkan hasil diskusi; (h) mengerjakan tugas evaluasi.

3) Pembelajaran IPA melalui model Picture and Picture berbantu media audio visual di kelas 3 SDN Citembong 01 Bantarsari dapat meningkatkan hasil belajar siswa. Hal ini ditunjukkan dengan perolehan data hasil belajar siswa pada siklus I nilai rata-rata hasil belajar siswa dengan persentase ketuntasan belajar klasikal sebesar $48,73 \%$. Pada siklus II terjadi peningkatan nilai rata-rata hasil belajar dengan persentase ketuntasan belajar klasikal sebesar 82,61\%. Pada Siklus III terjadi peningkatan nilai ratarata hasil belajar Peserta didik dengan persentase ketuntasan belajar klasikal sebesar 95,65\%. Hasil belajar IPA sudah memenuhi indikator keberhasilan yaitu $\geq 80 \%$ siswa kelas 3 mengalami ketuntasan belajar klasikal sebesar $\geq 68$.

Dengan demikian maka hipotesis tindakan telah terbukti bahwa model Picture and Picture berbantu media audio visual dapat meningkatkan kualitas pembelajaran yang terdiri dari keterampilan guru, aktivitas siswa dan hasil belajar IPA di kelas 3 SDN Citembong 01 Bantarsari Kabupaten Cilacap.

DAFTAR PUSTAKA

Aqib, Zaenal. 2010. Penelitian Tindakan Kelas. Bandung: Yrama Widya. 
Arikunto, Suharsimi. 2008. Penelitian Tindakan Kelas. Jakarta: Bumi Aksara.

Arsyad, Azhar. 2009. Media Pembelajaran. Jakarta: PT Rajawali Pers..

BSNP. 2006. Standar Isi IImu Pengetahuan Alam untuk SD/MI. Jakarta : Depdiknas.

Cain, E. Sandra dan Evans, M. Jack. 1990. Sciencing An Involvement Approach to Elementary Science Methods. Columbus: Merrill Publishing Company.

Daryanto. 2013. Media Pembelajaran. Yogyakarta: Gava Media.

Depdiknas. 2003. Undang-undang Republik Indonesia Nomor 20 tahun 2003 tentang Sistem Pendidikan Nasional. Jakarta: Depdiknas. 2004. Peningkatan Kualitas Pembelajaran. Jakarta: Depdiknas.

2006. Kurikulum Tingkat Satuan Pendidikan, Standar Kompetensi Mata Pelajaran IPA SD/MI. Jakarta: Depdiknas.

2007. Naskah Akademik Kajian Kebijakan Kurikulum Mata Pelajaran IPA. Jakarta: Depdiknas Badan Penelitian dan Pengembangan Pusat Kurikulum.

Dewiki dan Yuniati. 2006. IImu Alamiah Dasar. Jakarta: Universitas Terbuka.

Djamarah, Syaiful Bahri. 2010. Guru dan Anak Didik dalam Interaksi Edukatif. Jakarta: Rineka Cipta.

Ela, Neng. 2013. Penerapan Model Picture and Picture pada Pembelajaran IPA Materi Perubahan Lingkungan dan Pengaruhnya untuk Meningkatkan Hasil Belajar Peserta didik. Jurnal Universitas Pendidikan Indonesia. Vol. 2 (7): 52-58.

Funk, HS.et.al. 1979. Learning Science Process Skill. Lowa: Kendall/ Hunt publishing company.

Hamalik, Oemar. 2014. Proses Belajar Mengajar. Jakarta: Bumi Aksara.

Hamdani. 2011. Strategi Belajar Mengajar. Bandung : CV. Pustaka Ceria.

Haryono. 2013. Pembelajaran IPA yang Menarik dan Mengasyikkan. Yogyakarta: Kepel Press.

Herrhyanto dan Hamid. 2008. Stastika Dasar. Jakarta: Universitas Terbuka.

Johnson, Dawid W. 2012. Cooperative Learning Methods: A Meta-Analysis. University of Minnesota: Journal of Statistics Education. Vol.21 (1): 34-50.

Kustandi, Cecep dan Sutjipto Bambang. 2011. Media pembelajaran. Bogor: Ghalia Indonesia.

Kustiono. 2010. Media Pembelajaran. Semarang : UNNES Press.

Lapono, Nabisi. 2008. Belajar dan Pembelajaran SD. Jakarta: Direktorat Jendral Pendidikan Tinggi Departemen Pendidikan Nasional.

LiteraturAnitah, Sri, dkk. 2009. Strategi Pembelajaran di SD. Jakarta: Universitas Terbuka

Mardapi, Djemari. 2008. Teknik Penyusunan Instrumen Tes dan Non Tes. Yogyakarta: Mitra Cendikia Press.

Marno, dan Idris. 2012. Strategi dan Metode Pengajaran. Yogyakarta: Ar-ruzz Media.

Moerwani, Ninik Sri. 2011. Penggunaan pembelajaran kooperatif model picture and picture untuk meningkatkan hasil belajar IPA pada Peserta didik kelas IV Semester 1 SD Negeri 2 Jatipohon Kecamtan Grobogan Kabupaten Grobogan Tahun 2011/2012. Jurnal Universitas Kristen Satya Wacana. Vol. 1 (1): 2-12.

Nugroho, Junaedi. 2011. Pemanfaatan media audio visual untuk meningkatkan pembelajaran IPA pada Peserta didik Kelas 3 SDN Kemiriswu 2 Pasuruan. Jurnal Universitas Malang. Vol. 1 (1): 5-14.

Ode, Elijah Ojowu. 2014. Direct Of Audio Visual (AVs) Resources On Teaching And Learning In Some Selected Privat Secondary School In Makurdi.

Poerwanti, Endang, dkk. 2008. Asesmen Pembelajaran SD. Jakarta: Direktorat Jendral Pendidikan Tinggi Departemen Pendidikan Nasional.

Rifa'i, Achmad dan Catharina Tri Anni. 2011. Psikologi Pendidikan. Semarang: UNNES Press.

Rusman. 2012. Model-Model Pembelajaran Mengembangkan Profesionalisme Guru. Jakarta: Raja Grafindo Persada. 
Saleh, Nuraini. 2012. Penerapan Pembelajaran Picture and Picture untuk Meningkatkan Hasil Belajar IPA Kelas IV SDN 27 Pontianak Tenggara. Jurnal Universitas Tanjungpura. Vol. 4 (2): 13-23.

Sardiman. 2011. Interaksi dan Motivasi Belajar Mengajar. Jakarta: Raja Grafindo Persada.

Sardiman. 2012. Interaksi dan Motivasi Belajar Mengajar. Jakarta: Rajawali Press. Seels, Babara B. and Richey, Rita C.Richey. 1994. Teknologi Pembelajaran. Terjemahan Dewi S. Prawiradilaga, dkk. Jakarta : UNJ Press.

Shoimin,Aris. 2014. 68 Model Pembelajaran Inovatif dalam Kurikulum 2013. Yogyakarta: Ar-Ruzz Media.

Slameto. 2013. Belajar dan faktor-faktor yang mempengaruhinya. Jakarta: PT.Asdi Mahastya.

Suprijono, Agus. 2014. Cooperative learning. Yogyakarta: Pustaka Belajar.

Susanto, Ahmad. 2013. Teori Belajar dan Pembelajaran. Jakarta: Kencana Prenadamedia Grup.

Sutrisno, Leo dkk. 2007. Pengembangan Pembelajaran IPA SD. Jakarta: Direktorat Jendral Pendidikan Tinggi Departemen Pendidikan Nasional. Tarmidi. 2006. Iklim Kelas

Trianto. 2011. Model-Model Pembelajaran Inovatif Berorientasi Konstruktivistik. Jakarta: Prestasi Pustaka.

Utami, Anita Esti. 2013. Penggunaan Media Audio Visual Untuk Meningkatkan Kemampuan Mendeskripsikan Daur Hidup Hewan. Jurnal Universitas Sebelas Maret. Vol. 1 (5): 14-22.

Widoyoko, Eko Putro. 2013. Teknik Penyusunan Instrumen Penelitian. Yogyakarta: Pustaka Belajar.

Wulandari , Baktiyas Dwi. 2012. Upaya Peningkatan Motivasi Belajar IPA Kelas III Melalui Penggunaan Media Audio Visual Di SD Negeri Donokerto. Jurnal Universitas Negeri Yogyakarta. Vol. 4 (1): 7-16. 